ORIGINAL ARTICLE

\title{
Can all neonatal resuscitation be managed by nurse practitioners?
}

L C Chan, E Hey

See end of article for authors' affiliations

.....................

Correspondence to: Sister Chan, Maternity Unit, Wansbeck Hospital, Ashington,

Northumberland NE63

9JJ, UK; lai.chan@

northumbria-healthcare. nhs.uk

Accepted 8 August 2005

Published online first

30 August 2005
Aim: To assess the ability of nurse practitioners to manage the care of all babies requiring resuscitation at birth in a unit without on site medical assistance.

Method: A prospective review, and selective external audit, of the case records of all 14572 babies born in a maternity unit in the north of England during the first eight years after nurse practitioners replaced resident paediatric staff in 1996.

Results: Every non-malformed baby with an audible heart beat at the start of delivery was successfully resuscitated. Twenty term babies and 41 preterm babies were intubated at birth. Eight term babies only responded after acidosis or hypovolaemia was corrected following umbilical vein catheterisation; in each case the catheter was in place within six minutes of birth. Early grade 2-3 neonatal encephalopathy occurred with much the same frequency $(0.12 \%)$ as in other recent studies. Independent external cross validated review found no case of substandard care during the first hour of life.

Conclusion: The practitioners successfully managed all the problems coming their way from the time of appointment. There was no evidence that their skill decreased over time even though, on average, they only found themselves undertaking laryngeal intubation once a year. It remains to be shown that this level of competence can be replicated in other settings.

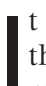
has often been said that more die on the first day of life than any other-except the last. Yet, despite this, there is much concern as to the experience and skill of the paediatricians called on to manage these problems. Concerns about the quality of resuscitation were raised in $22 \%$ of all the neonatal deaths selected for confidential inquiry in the United Kingdom because of intrapartum events in 1994-5. ${ }^{1}$ For these and other reasons, many do not think that nurses and midwives should be expected to cope with these problems. Any such generalisation may, however, be inappropriate. Two recent studies have certainly shown that nurse practitioners working in a large referral centre can manage neonatal resuscitation very competently. ${ }^{23}$ The present study set out to show whether a practitioner working in a smaller unit can expect to gain and retain these skills, when they only find themselves passing an endotracheal tube once a year.

\section{SETTING AND STUDY METHODS}

Neonatal nurse practitioners became responsible for all aspects of post-delivery care of the babies born in the obstetric unit at Ashington Hospital when recognition for the training content of the hospital's paediatric residency post was withdrawn in 1996. All on site care has, since then, been provided by one of six (later eight) nurse practitioners, with access at all times to advice from a consultant in the nearest neonatal referral centre 17 miles away. A full description of how the service now functions has recently appeared in this journal. ${ }^{4}$ The booking criteria used by the unit's five obstetricians are the same as those in the other 10 maternity units with no on site facilities for undertaking sustained neonatal intensive care in the region, and they did not change in 1996. A total of $160(1.1 \%)$ of the 14732 mothers originally booked for delivery in Ashington ended up being referred elsewhere for care before delivery during the eight years covered by this review (1996-2003 inclusive), usually because delivery seemed likely before 31 weeks gestation.
The existence of an on site neonatal nursery made the need for post-delivery transfer equally uncommon.

All the practitioners coming into post had at least four years previous experience of neonatal nursing. All had been through a course with a syllabus identical with the one that now forms the basis of the UK Resuscitation Council's Neonatal Life Support course before coming into post, ${ }^{5}$ but two had never intubated a live baby, and none had ever done this more than half a dozen times. Only three had ever intubated a live baby when there was someone else present to supervise them and to help them through the procedure.

A prospective record was kept of all babies requiring resuscitation throughout the study period, and information on the perinatal outcome of every pregnancy where the mother originally booked for delivery in Ashington was obtained from the regional maternity survey office. ${ }^{6}$ The case records of every neonatal (0-27 day) death, every baby developing an encephalopathy, and every term ( $\geqslant 37$ week gestation) baby undergoing laryngeal intubation, or taking more than five minutes to establish regular respiration were subjected first to internal audit and then to external scrutiny by at least one and sometimes two independent assessors (one of four consultant neonatologists with no responsibility for the unit or its development). Twenty cases were also subjected, after anonymisation, to secondary review by a multidisciplinary panel of clinicians from other parts of the region, ${ }^{7}$ and a further 10 of the most complex cases were reviewed, alongside a comparable number from four other medically staffed units, by a panel from another region ${ }^{8}$ blind to the unit of origin.

The case record required staff to document how long it took every baby to gasp or cry at birth, and to start breathing regularly, and how long it took for the heart rate to rise and stay above 100 beats/min. Effective aeration of the lung was judged to have been achieved once the heart rate was this high. It was also judged to have been achieved if, although bradycardia was not abolished, visible chest movement could be seen each time inflationary pressure was applied. 


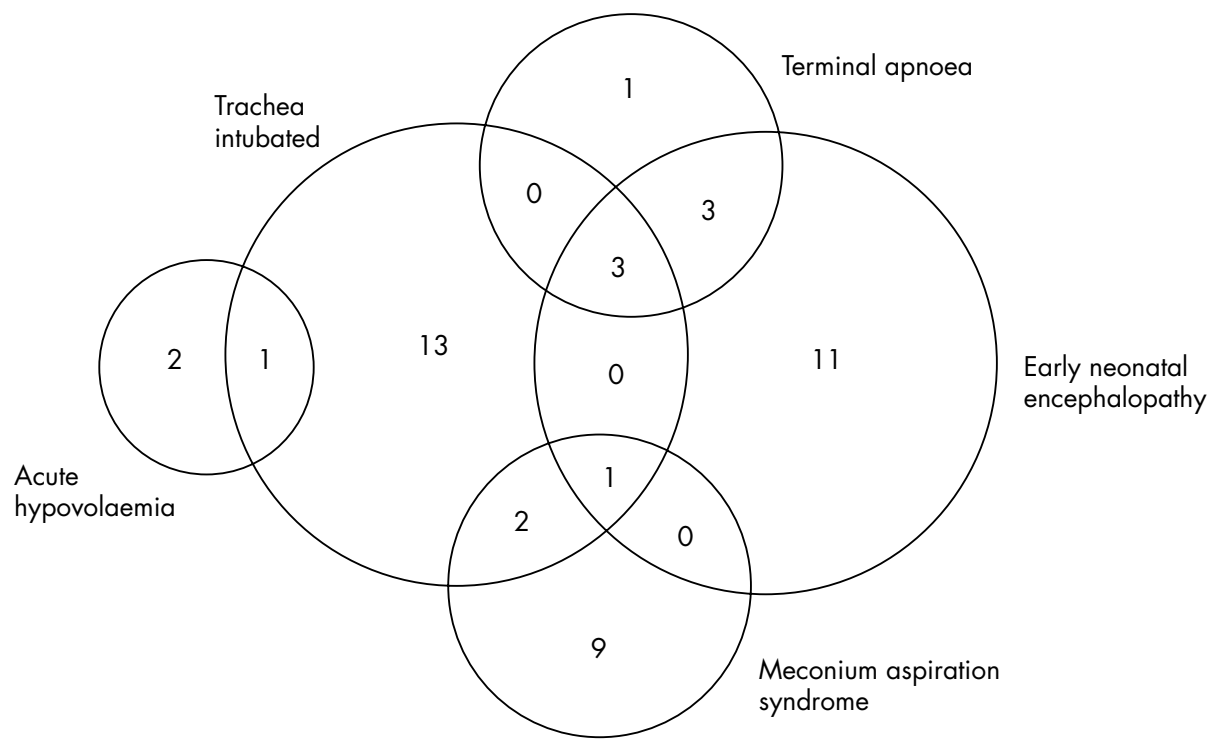

Figure 1 Problems encountered during resuscitation in 13514 term babies. Twenty babies were intubated, 18 developed grade 2-3 encephalopathy, 12 developed symptoms of meconium aspiration syndrome, and three had life threatening hypovolaemia at birth.

\section{RESULTS}

\section{Management of the term baby at birth}

Problems associated with delivery were encountered in 46 babies (summarised in fig 1). Mask inflation of the lung was used to initiate breathing in an estimated $6 \%$ of all the babies born at term, but few needed any further respiratory support once lung aeration had been achieved. Practitioners would still have been present for every baby managed by intubation (other than one child with shoulder dystocia) had they only attended operative deliveries for fetal distress. Such a policy would have freed them from attending four fifths of the term deliveries they did attend.

\section{Babies in terminal apnoea at birth}

Seven babies were judged, in retrospect, to have been in terminal apnoea at birth. One had no detectable heart beat for 12 minutes after birth. The others had a heart rate of less than 60 beats/min at delivery which did not rise until after the lung had been aerated. All only gasped for the first time after the heart rate had returned to normal. Chest compression was used in six, and in five of these the circulation only responded after sodium bicarbonate as well as adrenaline had been given down an umbilical vein catheter. They continued to gasp intermittently for at least one to two minutes before normal breathing movements were seen, and continued to gasp regularly for a further period after that. All had an umbilical blood pH below 6.8 and a base deficit of 16 or more at delivery. With one exception, all went on to develop a severe (grade 2-3) neonatal encephalopathy. Five have since died, and one has severe spastic quadriplegia. In no case had it taken more that two minutes to effect lung expansion, or six minutes to get the umbilical vein catheterised. Only three were intubated. The only unscathed survivor was a baby delivered 30 minutes after the onset of sudden progressive fetal bradycardia to a mother who suffered uterine rupture. That baby developed no sign of any encephalopathy, was well enough to go home after four days, and was developing normally one year later.

\section{Early neonatal encephalopathy}

Eighteen term babies developed signs of a grade 2-3 encephalopathy within 24 hours of birth. Ten were breathing regularly within two minutes of birth and were not judged to need active resuscitation at birth. One other baby was breathing regularly within four minutes after a brief period of mask resuscitation. None of these remained bradycardic for more than 90 seconds. Seven had a barely audible or inaudible heart beat at birth that did not rise after lung aeration, and were judged retrospectively to have been in terminal apnoea at birth. Assessors found no evidence to suggest that the long term outcome in these 18 children would have been affected by more prompt intervention or more effective care in the first hour of life. Five babies have since died, three have spastic quadriplegia, and another is deaf. No baby of less than 37 weeks gestation developed a severe encephalopathy during the years in question; prevalence among all term deliveries in the unit $(0.12 \%)$ is therefore much the same as in other recent case series. ${ }^{8-10}$ The rate for the 255000 babies of 35 or more weeks gestation born in the Trent region in England between 1998 and 2002 was $0.14 \%$ in $2000-02 .{ }^{11}$

\section{Hypovolaemic collapse at birth}

Three very pale bradycardic babies failed to respond to lung aeration and mask ventilation even though the specimen of cord blood showed no evidence of acidosis. All three gasped intermittently, but none breathed regularly after birth. In each case the heart rate remained below 70 beats/min even after lung aeration was achieved, but doubled within a minute as soon as the baby was given a bolus of at least $20 \mathrm{ml} / \mathrm{kg}$ saline, plasma, or blood through an umbilical catheter. All three babies were breathing normally within 22 minutes. In each case it was established retrospectively that the baby had almost certainly been acutely hypovolaemic at birth (as judged by a low red blood cell volume), the problem being due to cord prolapse in one baby, to shoulder dystocia in a second, and to a tight nuchal cord in a third. None of these babies went on to develop any serious features of an encephalopathy.

\section{Laryngeal intubation during initial resuscitation}

Only 20 term babies were intubated during resuscitation, although another 14 were intubated soon after the circulation had been restarted and breathing movements had been seen in order to facilitate continuing care. Early reintubation proved necessary in two babies because of tube dislodgement, 
and, in one baby, where there was a lot of blood stained fluid in the posterior pharynx obscuring the larynx, the anaesthetist in theatre came to the practitioner's assistance. Five babies were intubated at birth in the first half of 1996 (the year when nurse practitioners first assumed responsibility for all aspects of neonatal resuscitation). After 1996, intubation was only used in $0.13 \%$ (15/11 518) of term births.

Meconium was present in the liquor of eight of the 20 babies managed by direct laryngeal intubation at birth, but particulate matter was only found below the larynx in three. These three babies became oxygen dependent for at least 48 hours, as did another nine who had meconium in their liquor at birth, but who breathed within moments of delivery, and required no resuscitation. None of the other intubated babies remained oxygen dependent for more than four hours. In one other baby, with good cord gases, it proved impossible to elicit any chest movement at first, although the baby did respond rapidly once the trachea was intubated and a lot of thick creamy white material was removed. This baby (who had probably inhaled vernix) went on to make a rapid and uninterrupted recovery.

\section{Delayed onset of regular respiration}

Forty eight babies subjected to mask resuscitation only started to breathe regularly six or more minutes after birth, even though bradycardia never persisted for more than two minutes. In 17 cases, no problem had been expected, and no nurse practitioner was present at delivery. Another eight cases followed delivery under general anaesthesia. Maternal sedative medication may have been a factor in another three cases, and three other mothers were receiving methadone. None of these babies was seriously acidotic at birth, and none went on to develop fits or any other sign of an encephalopathic illness after birth, although two of the babies born to mothers receiving methadone later developed withdrawal symptoms.

\section{Management of the preterm baby at birth}

Figure 2 summarises the initial management of the 1058 preterm babies born in the hospital between 1996 and 2003.

Forty one preterm babies were intubated, including 29 of the 73 babies born at less than 30 weeks gestation. In only two of the preterm babies in whom intubation was the

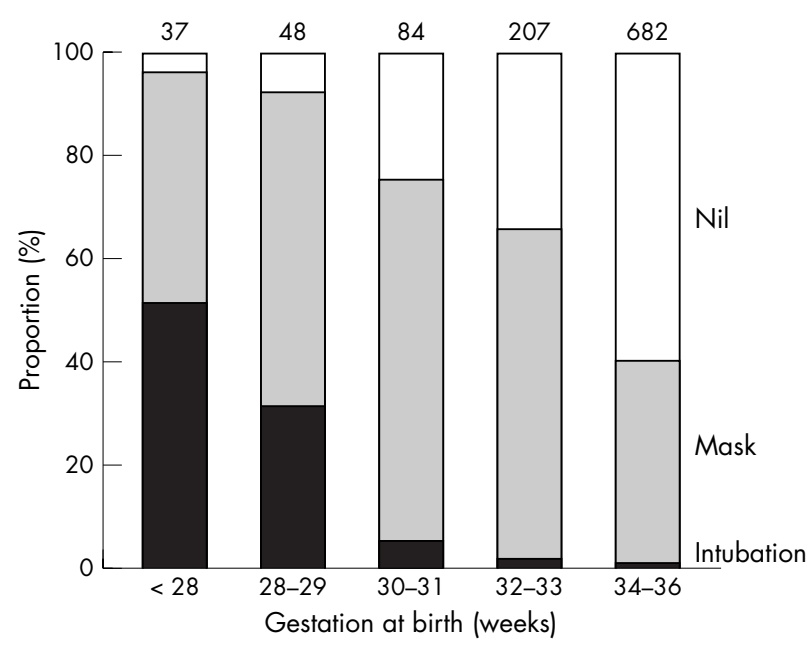

Figure 2 Management at birth in 1058 babies of less than 37 weeks gestation. The number at the top of each bar is the number of babies born in that gestational age band in the hospital between 1996 and 2003 inclusive. Medical staff from the regional transfer service were present and assisted with the immediate post-delivery and pre-transfer care of 18 of the babies of less than 30 weeks gestation. strategy adopted from the outset did it take more than two minutes to place an endotracheal tube. All but one of the 397 preterm babies managed by mask resuscitation at delivery was centrally pink within two minutes, and had a heart rate above 100 beats/min, although in 12 it took more than five minutes for the baby to start breathing regularly. Medical staff from the region's neonatal transfer service had, as a matter of policy, tried to be present in time to assist with the immediate post-delivery care of all babies born before 30 weeks gestation in the years before nurse practitioners first came into post but, by 1999, it was clear that this policy was no longer as necessary as it had originally been.

\section{Intrapartum and neonatal death}

Two term and three preterm babies died during labour but, with one exception, death occurred at least two hours before delivery, and this knowledge had been shared with the mother before delivery. In the remaining case, the fetal heart was detected beating on ultrasound immediately before caesarean delivery ( $\sim 35$ beats/min), but no heart beat could be detected at birth, and the cord blood had a pH of 6.65.

Neonatal mortality among babies actually born in the unit (31/14 572) was comparable to that for the other 10 units in the region ( $2.1 v 2.3$ deaths/1000 births). One term baby with a complex heart defect could not be resuscitated, one died with an intracranial bleed two days after an uneventful vertex delivery, and five died with features of intrapartum asphyxia (see above). Eighteen preterm babies died with hyaline membrane disease or its secondary consequences. Two of these were born at 29 weeks gestation; all the others were less than 28 weeks gestation at birth. Two preterm babies died of asphyxia following placental abruption. Two others died with lethal malformations, one died when the airway became compromised during transfer, and one baby, who needed no resuscitation at birth, died from delayed bleeding into the peritoneal cavity from a liver haematoma. Audit failed to find significant fault with the resuscitation and stabilisation of any of these babies before their transfer to a tertiary centre for continuing care.

\section{DISCUSSION}

Our data confirm that nurse practitioners working in an obstetric unit where there are no resident paediatric staff can become and remain proficient in neonatal resuscitation. The change in staffing had no detectable impact on neonatal mortality either among the babies actually delivered in the unit (as reported here), or among all the babies originally booked for delivery in the unit. ${ }^{12}$ More convincingly, independent external audit showed that resuscitation was being undertaken in an appropriate, timely, and efficient way.

The frequency with which laryngeal intubation is undertaken in the term baby is probably a reflection of the confidence that staff have in the efficacy of mask resuscitation at birth. The UK's first training manuals all focused on intubation as being the most effective method of securing lung aeration, mainly because most face masks in use before 1984 provided a very poor face seal. However, after the development of the Laerdal face mask, ${ }^{13}$ a study in Sweden found that, among babies weighing $2500 \mathrm{~g}$ or more at birth, skilled staff only judged one baby in every 600 to need intubation at birth. ${ }^{14}$ This finding has been confirmed in this study, where only one term baby in 800 was managed by intubation at birth.

A small minority of babies are always going to need intubation at birth, however, and it is reassuring to see that staff found that they had the skill to do this when necessary, even though they came into post with little previous experience of laryngeal intubation. It is equally important 


\section{What is already known on this topic}

- Staff take time to become skilled in neonatal resuscitation

- There is a widespread perception that this skill wanes when not put to regular use

to record that there is no evidence to suggest that this skill later deserted them even though individual staff only found themselves intubating an average of one baby a year. Confidence waned when this skill was not called on often, but competence did not-the reverse of what studies using simulation rather than an audit of actual practice to assess skill retention have reported until now. ${ }^{15-20}$ If this finding can be replicated in other settings, it has important implications for the many midwives who have progressively lost confidence in their ability to sustain this skill in the last 30 years.

In the first few years after nurse practitioners first replaced resident paediatric staff in Ashington, they assumed responsibility for stabilising all the sickest babies at delivery. Once this training became more widely available, this responsibility came to be shared flexibly with the midwives, and this team approach may well account, at least in part, for the speed with which umbilical vein catheterisation was always achieved when judged necessary. An anaesthetist was present in theatre during the delivery of many of the illest babies, but they only took an active part in the resuscitation of three of the babies in this study (all born in the first third of the study period). Although an anaesthetist assisted with laryngeal intubation on two occasions, this reversal of responsibility does not seem to have been critical to successful case management. In two thirds of the preterm babies of more than 29 weeks gestation, early lung expansion was optimised by gentle controlled mask inflation at birth, ${ }^{21}$ and in some this was then sustained by offering early nasal continuous positive airway pressure. Only $1.6 \%$ were judged to need intubation at birth.

Learning how to intubate the trachea seems to be rather like learning to ride a bicycle. It looks somewhat improbable to the onlooker, and it is a skill that cannot be learnt from a book. It can only be acquired by trying to do it while-with luck-a supportive colleague stands by. It is, however, a skill that, once acquired, is never lost.

\section{ACKNOWLEDGEMENTS}

We are grateful to the unit's part time research nurse, Kathleen Davidson, for her maintenance of the database on which this review is based, and to Marjorie Renwick in the regional Maternity Survey Office for mortality data. We are also grateful to anonymous colleagues in the north of England for access to comparator data and for their help with the cross validation of study outcomes, and to colleagues in Trent for their blinded assessment of 20 of the more complex case files. The practitioners in Ashington wish to place on record their appreciation of all the support they have received from the consultant to the unit, Dr U K Wariyar, over the last eight years.

\section{Authors' affiliations}

L C Chan, Maternity Unit, Wansbeck Hospital, Ashington,

Northumberland, UK

E N Hey, Retired Paediatrician, Newcastle, UK

\section{What this study adds}

- Experienced nurses were externally judged to have managed all the care required by the 14500 babies born in an obstetrically staffed maternity unit to a high standard over an eight year period even though the unit lacked any on site paediatric staff

- Laryngeal intubation was only used in the initial resuscitation of $61(0.4 \%)$ of these term and preterm babies, and staff found that, although confidence in their ability to do this waned when it was seldom needed, competence did not

Competing interests: LCC has worked in the unit where this work was undertaken since 1998. ENH was the first to suggest that nurse practitioners might be used to replace resident medical staff when the unit first faced closure in 1993, but he had retired before the practitioners came into post in 1996.

\section{REFERENCES}

1 Maternal and Child Health Consortium. Confidential enquiry into stillbirths and deaths in infancy: 4th annual report, 1995. London: Maternal and Child Health Consortium, 1997:45-9.

2 Mitchell-DiCenso A, Guyatt G, Marrin M, et al. A controlled trial of nurse practitioners in neonatal intensive care. Pediatrics 1996;98:1143-8.

3 Yoxall CW, Aubrey WR. Evaluation of the role of the neonatal nurse practitioner in resuscitation of preterm infants. Arch Dis Child 2001;85:F96-9.

4 Hall D, Wilkinson AW. Quality of care by neonatal nurse practitioners: a review of the Ashington experiment. Arch Dis Child 2005;90:F195-200.

5 Resuscitation Council (UK). Resuscitation at birth. The newborn life support course manual. London: Resuscitation Council, 2001.

6 Northern Regional Health Authority Coordinating Group. Perinatal mortality: a continuing collaborative region survey. BMJ 1984;288:1717-20.

7 Ward Platt MP, Brown K. Evaluation of advanced neonatal nurse practitioners: confidential enquiry into the management of sentinel cases. Arch Dis Child Fetal Neonatal Ed 2004;89:F241-4.

8 Draper ES, Kurinczuk JJ, Lamming CR, et al. A confidential enquiry into cases of neonatal encephalopathy. Arch Dis Child Fetal Neonatal Ed 2001;87:F176-80.

9 Smith J, Wells L, Dodd K. The continuing fall in the incidence of hypoxicischaemic encephalopathy in full-term infants. $\mathrm{Br} J$ Obstet Gynaecol 2000; 107:461-6.

10 Thornberg E, Thiringer K, Odeback A, et al. Birth asphyxia: incidence, clinical course and outcome in a Swedish population. Acta Paediatr 1995;84:927-32.

11 Trent Neonatal Survey. Annual report, 2002. Leicester: University of Leicester, 2003, table 26).

12 The Ashington Audit Group. Evaluation of a nurse-led model for providing neonatal care. J Adv Nurs 2004;47:39-48.

13 Palme C, Nystrom B, Tunnell R. An evaluation of the efficiency of face-masks in the resuscitation of newborn infants. Lancet 1985;i:207-10.

14 Palme-Kilander C. Methods of resuscitation in low Apgar score in newborn infants: a national survey. Acta Paediatr 1992;81:739-44.

15 Stross JK. Maintaining competency in advanced cardiac life support. JAMA 1983;249:3339-41

16 Kaye W, Mancini ME. Retention of cardiopulmonary resuscitation skills by physicians, registered nurses, and the general public. Crit Care Med 1986;14:610-12

17 Kaye W, Wynne G, Marteau T, et al. An advanced resuscitation training course for preregistration house officers. J R Coll Phys 1990;24:51-4.

18 Dunn S, Niday P, Watters NE, et al. The provision and evaluation of a neonatal resuscitation program. J Contin Educ Nurs 1992;23:118-26.

19 Broomfield R. A quasi-experimental research to investigate the retention of basic cardiopulmonary resuscitation skills and knowledge by qualified nurses following a course of professional development. J Adv Nurs 1996;23:1016-23.

20 Kaczorokoski J, Levitt C, Hammond M, et al. Retention of neonatal skills and knowledge: a randomised controlled trial. Fam Med 1998;30:705-11.

21 O'Donnell CPF, Davis PG, Morley CJ. Resuscitation of premature infants: what are we doing wrong and can we do better? Biol Neonat 2003;84:76-82. 